\title{
The Magnesium Hatchback of the 3-Liter Car: Processing and Corrosion Protection
}

\author{
Harald Schreckenberger, Matthias Papke and Stephan Eisenberg
}

Volkswagen AG 
The appearance of this ISSN code at the bottom of this page indicates SAE'S consent that copies of the paper may be made for personal or internal use of specific clients. This consent is given on the condition, however, that the copier pay a $\$ 7.00$ per article copy fee through the Copyright Clearance Center, Inc. Operations Center, 222 Rosewood Drive, Danvers, MA 01923 for copying beyond that permitted by Sections 107 or 108 of the U.S. Copyright Law. This consent does not extend to other kinds of copying such as copying for general distribution, for advertising or promotional purposes, for creating new collective works, or for resale.

SAE routinely stocks printed papers for a period of three years following date of publication. Direct your orders to SAE Customer Sales and Satisfaction Department.

Quantity reprint rates can be obtained from the Customer Sales and Satisfaction Department.

To request permission to reprint a technical paper or permission to use copyrighted SAE publications in other works, contact the SAE Publications Group.

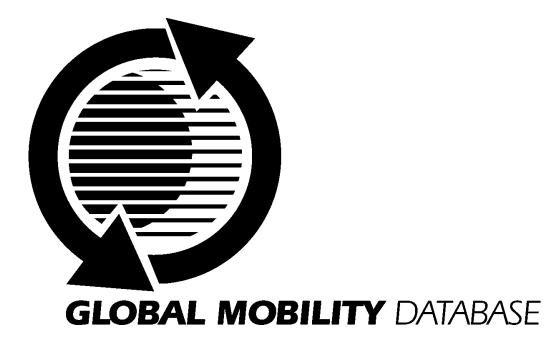

All SAE papers, standards, and selected books are abstracted and indexed in the Global Mobility Database

No part of this publication may be reproduced in any form, in an electronic retrieval system or otherwise, without the prior written permission of the publisher.

ISSN 0148-7191

Copyright 2000 Society of Automotive Engineers, Inc.

Positions and opinions advanced in this paper are those of the author(s) and not necessarily those of SAE. The author is solely responsible for the content of the paper. A process is available by which discussions will be printed with the paper if it is published in SAE Transactions. For permission to publish this paper in full or in part, contact the SAE Publications Group.

Persons wishing to submit papers to be considered for presentation or publication through SAE should send the manuscript or a 300 word abstract of a proposed manuscript to: Secretary, Engineering Meetings Board, SAE.

\section{Printed in USA}




\title{
The Magnesium Hatchback of the 3-Liter Car: Processing and Corrosion Protection
}

\author{
Harald Schreckenberger, Matthias Papke and Stephan Eisenberg \\ Volkswagen AG
}

Copyright (C) 2000 Society of Automotive Engineers, Inc.

\begin{abstract}
The hatchback of Volkswagen's 3 liter car ( 3 I fuel consumption per $100 \mathrm{~km}$ ) consists of an inner component of die casting magnesium (AM50) covered with an aluminum panel from the outside. This hybrid design requires a new manufacturing process: The pre-coated magnesium part will be bonded and folded with the bare aluminum part. Corrosion protection is provided by an organic coating system which both protects against general corrosion and galvanic corrosion.
\end{abstract}

The corrosion of the Al / Mg sandwich has been examined with hybrid samples which are similar to the hatchback. Several powder coatings (epoxy resin, polyester resin, hybrid resin), wet paints and cathodic electro-coating paints of different thicknesses and compositions have been applied to the magnesium part. They show that only powder coating provides adequate protection. Galvanic corrosion at the points of attachment of the hatchback might be possible (for example the bolted joint of the hinge). Resistance against galvanic corrosion has been tested with samples that had a damaged paint coat in order to simulate a defect. Furthermore different contact elements ( $\mathrm{Fe}, \mathrm{Al}, \mathrm{Zn}$, etc.) have been attached with electrically conductive fixings. Under laboratory conditions, all test samples where subjected to a corrosion load of 30 cycles in the environmental corrosion test.

\section{INTRODUCTION}

Magnesium components play an important role at Volkswagen. For example, nearly every transmission housing is cast in magnesium. Magnesium parts are lightweight and therefore reduce fuel consumption and offer many opportunities for lightweight design of motor vehicles. It has even become possible to manufacture large, thinwalled body elements using magnesium. These can be used in place of the usual steel-panel construction.

You can also find a magnesium body structure in Volkswagen's 3-liter car, the Lupo TDI. Light-metal construction in the 3 liter automobile relies on the use of magnesium and aluminum. The box section frame of the initial body assembly is made as usual of steel panels.
The add-on parts are made of aluminum. The hood, the doors and the outer panel of the hatchback are made of sheet aluminum. The rear brake drums are especially worthy of attention: They are made of fiber-reinforced aluminum and are among the lightest brake drums in the world.

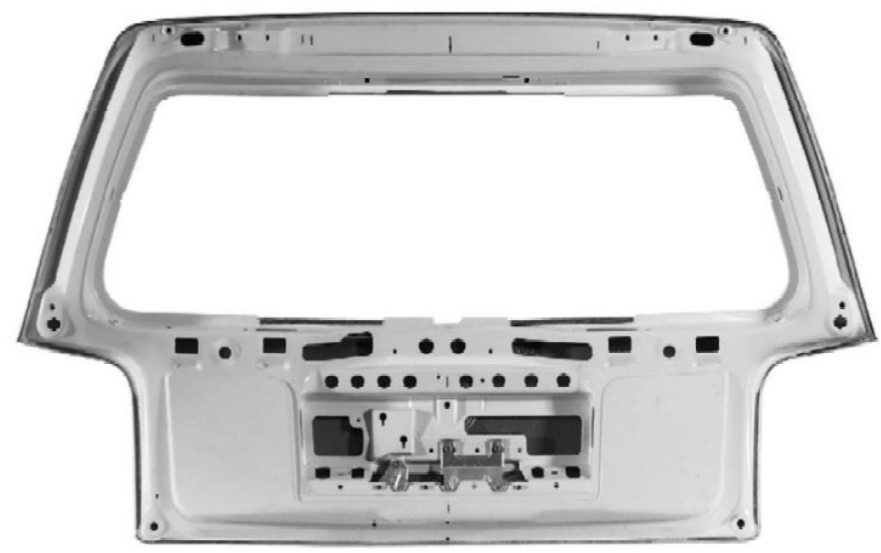

Figure 1. The $\mathrm{Mg} / \mathrm{Al}$ Hybrid Hatchback

Magnesium can be found in two places on this vehicle. First, there is the magnesium steering wheel frame, but that is not a new component - it was an existing feature of the Golf. What is really new is that magnesium has been used for the inner component of the hatchback (Figure 1).

The hatchback is a hybrid construction with outer panel made of aluminum and inner component made of magnesium. When painted, the magnesium part looks and feels like sheet metal but is in actual fact the product of diecasting. The parts are assembled in a folding and bonding process. AM50 alloy was chosen for the magnesium part because it represented a good compromise between the properties needed for casting, tensile strength and ductility. The component is between 1.6 and $3.5 \mathrm{~mm}$ thick, and the total weight is only $2.8 \mathrm{~kg}$. A $3300-$ to machine is used for the diecasting, operated by the firm Mössner. A weight comparison clearly illustrates the advantage of hybrid construction: The $\mathrm{Al} / \mathrm{Mg}$ hatchback weighs $5.4 \mathrm{~kg}$. The steel hatchback of the normal Lupo weighs twice as much. An Al-Al hatchback developed as a backup solution weighs $8.5 \mathrm{~kg}$. 
Magnesium is known to be a material which is highly susceptible to corrosion. The car body is also known to be susceptible to corrosion. Thus, an anti-corrosion system had to be developed for the hybrid construction, in a process that systematically tested variously coated sample objects.

\section{EXPERIMENTAL WORK}

SPECIMEN - The fold connections of the body elements are susceptible to corrosion. Due to the application technique, only a thin paint coat can be applied at these points and moisture may also accumulate there. The hybrid sample as illustrated in Fig. 2 simulates such a fold junction. A coated magnesium plate (thickness $2 \mathrm{~mm}$ ) of the diecast alloy AM50 HP is joined to an aluminum sheet (AIMg0,4Si1.2) by folding and bonding (epoxy resin adhesive).

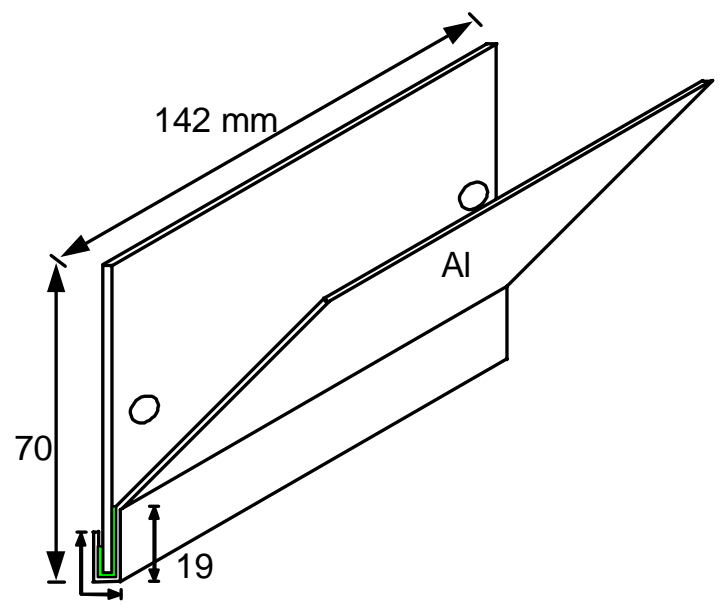

14

Figure 2. Hybrid sample

The danger of galvanic corrosion of the magnesium components when the paint is damaged at the junction points was investigated with contact bodies. Fig. 3 shows the composition of the contact body. The key features are a) the scratch on the coated magnesium sheet and $b$ ) the contact element attached with electrically conductive fixings. Five different contact elements with various degrees of galvanic compatibility [5] are fixed to the magnesium plates by electrically conductive screws.

COATINGS - The organic layer system exercises an important influence on the corrosion characteristics of the aluminum-magnesium composite structure. According to the literature, several paint systems are classified as being suitable for magnesium components [1;2].

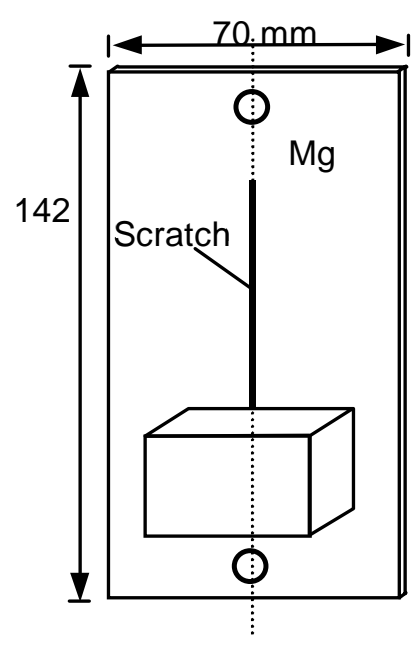

Contact elements:

1. Steel St37

Steel St37 coated with

2. Dacromet

3. Zinc + yellow chromated

4. Zinc + yellow chromated + sealed (JS500)

5. Aluminum AIMg3
Table 1. Test matrix of the different coating systems

\begin{tabular}{|c|c|c|c|c|c|c|c|c|c|c|c|c|}
\hline 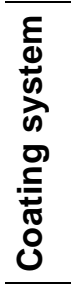 & 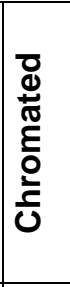 & 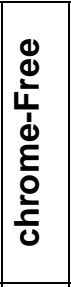 & $\begin{array}{l}\bar{\pi} \\
0 \\
0 \\
d\end{array}$ & $\begin{array}{l}- \\
\frac{1}{0} \\
0 \\
\vdots \\
0 \\
0\end{array}$ & $\begin{array}{l}\text { N } \\
\frac{1}{0} \\
\frac{0}{0} \\
\vdots \\
0\end{array}$ & $\begin{array}{l}m \\
\frac{3}{2} \\
\frac{0}{0} \\
3 \\
0 \\
0\end{array}$ & $\begin{array}{l}+ \\
\frac{1}{0} \\
0 \\
\vdots \\
0 \\
\varrho\end{array}$ & $\begin{array}{l}10 \\
\frac{1}{0} \\
0 \\
\vdots \\
0 \\
0 \\
0\end{array}$ & $\begin{array}{l}0 \\
\vdots \\
0 \\
0 \\
\vdots \\
0 \\
0\end{array}$ & 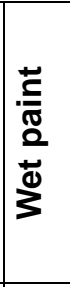 & $\begin{array}{l}\frac{1}{d} \\
\frac{0}{3} \\
\vdots \\
0\end{array}$ & 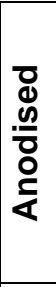 \\
\hline 1 & $x$ & & $x$ & $X$ & & & & & & & & \\
\hline 2 & $x$ & & $X$ & & $X$ & & & & & & & \\
\hline 3 & $x$ & & $X$ & & & $x$ & & & & & & \\
\hline 4 & $x$ & & $X$ & & & & $x$ & & & & & \\
\hline 5 & $x$ & & $X$ & & & & & $x$ & & & & \\
\hline 6 & $x$ & & $X$ & & & & & & $x$ & & & \\
\hline 7 & $x$ & & & & & & & & & $x$ & & \\
\hline 8 & $x$ & & & & & & & & & $x$ & $X$ & \\
\hline 9 & $x$ & & $x$ & $X$ & $x$ & & & & & & & \\
\hline 10 & $x$ & & $X$ & & $X$ & $x$ & & & & & & \\
\hline 11 & $x$ & & $X$ & & & & & & & & & \\
\hline 12 & $x$ & & & $X$ & & & & & & & & \\
\hline 13 & & $x$ & $x$ & & $x$ & & & & & & & \\
\hline 14 & & & & & & & & & & & & $X$ \\
\hline
\end{tabular}

Preliminary investigations by the Volkswagen Group indicate that only the layer pattern chromation + e-coat + powder coating provides effective protection for magnesium body components. 
In total, six different powder coating types and one wet paint system were tested. All paints and process materials used are listed in Table $A / 1$. The combination of individual layers to form a total of 14 different coating systems is represented in the test matrix in Table 1 . The pre-defined desired thickness of the e-coat (cathodic electro-coating paint) is $20 \mu \mathrm{m}$ and that of the powder coating $80 \mu \mathrm{m}$. At polished cross sections an average powder coating thickness of about $110 \mu \mathrm{m}$ was measured. The coated magnesium plates were used to form a) the hybrid body and b) the contact body. Nine similar hybrid bodies and three similar contact bodies were thereby produced for each coating system, to ensure that the test results were statistically reliable.

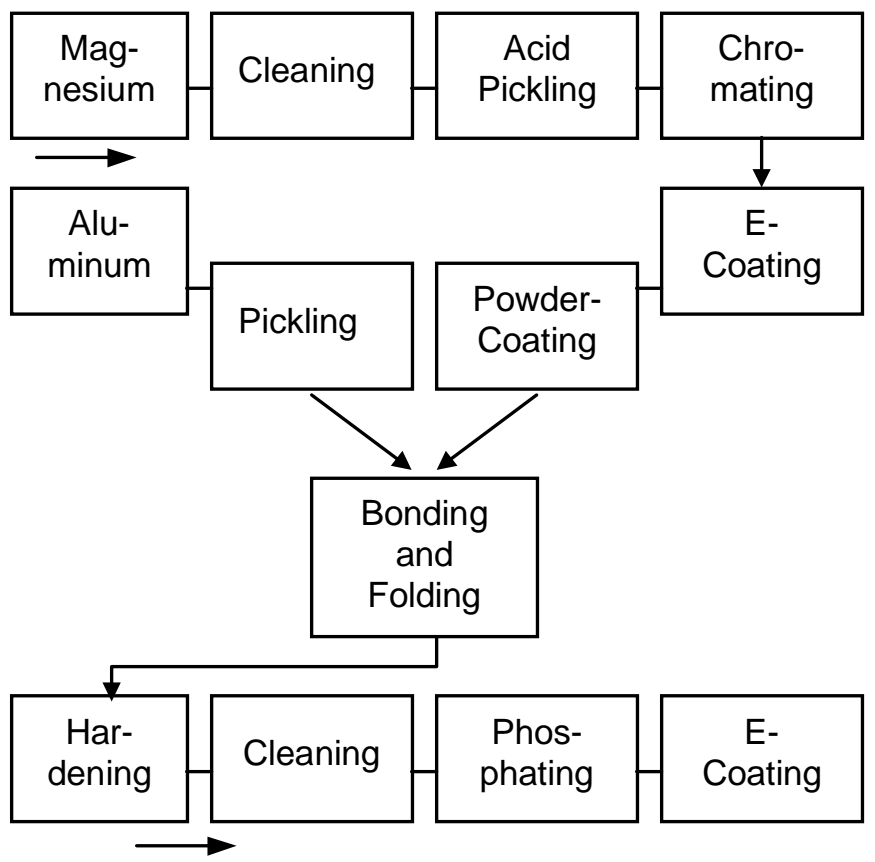

Figure 4. Process diagram

Fig. 4 shows the process diagram for coating magnesium panels and hybrid bodies. As a first step, the magnesium panels are degreased and rinsed. Then roughly 20 to 30 $\mu \mathrm{m}$ of the casting crust is removed in an acid bath and the external residues of the casting process, such as lubricants are also removed. This produces an uniform and even surface condition and improves paint adhesion and the quality of finish [3]. Then the panel is rinsed, yellow chromated and dried. The process chemicals are applied in this first sequence in the spray process. The ecoat is applied in another system and baked for $15 \mathrm{~min}-$ utes at $180^{\circ} \mathrm{C}$. Finally the powder coating is applied by a spraygun with the EPS process. The coat is baked at average temperatures of $200^{\circ} \mathrm{C}$ for 10 to 15 minutes.

The oxidation status of the aluminum panels is standardized by pickling before the jointing process. The hybrid bodies are now formed by folding and bonding and then adhesive and aluminum panel is baked in the oven for 20 minutes at $205^{\circ} \mathrm{C}$. In the next process step, the hybrid body is put through the e-coat in the steps degreasing, phosphatization, e-coat application and baked at $180^{\circ} \mathrm{C}$ for 14 minutes. Only the aluminum sheet in the process absorbs e-coat as the magnesium panel is electrically insulated by the coating powder. The special feature of the selected coating sequence is that a pre-coated component undergoes a process which was specifically developed for uncoated components. When the hybrid bodies passes through the e-coat, noticeable blistering occurs with powder coatings 5 and 6 .

TEST CONDITIONS - The corrosive load was determined under laboratory conditions in the corrosion chamber. Tests were run according to the Volkswagen testing regulation PV 1210. One test cycle lasts a day. The samples are first subjected to 4 hours of salt fog at $35^{\circ} \mathrm{C}$. They are then dried for 4 hours at room temperature. For the remainder of the day, the samples are stored in condensing humidity at $40^{\circ} \mathrm{C}$. No testing was performed at weekends, and the samples are stored in the normal ambient climate. The temperature and humidity fluctuations cause the paint to swell and contract, creating additional load on the material. The chlorides promote corrosion. After 30 cycles - or after six weeks - the test was ended and the test objects were evaluated. To pass the test, the sample may show no signs of corrosion and no signs of blister formation. Existing scratches were only slightly propagated.

\section{RESULTS}

HYBRID SAMPLES - The hybrid system requires the bonding of a heterogeneous material pair. The joint area, which adjoins a hollow space, is in the form of a bonded fold joint, which is especially susceptible to corrosion. This is illustrated by Fig. 5, which presents a hybrid body without coating after 30 cycles of the environmental corrosion test PV1210. The contact zone between the uncoated aluminum plate and the uncoated magnesium panel is occupied by a thick layer of white corrosion products. It is essential to pre-coat the magnesium component to mutually isolate the two materials. Outside the contact zone, less corrosion is evident, here we are dealing with surface corrosion, which is more apparent with magnesium than with aluminum. After processing, however the situation is radically different.

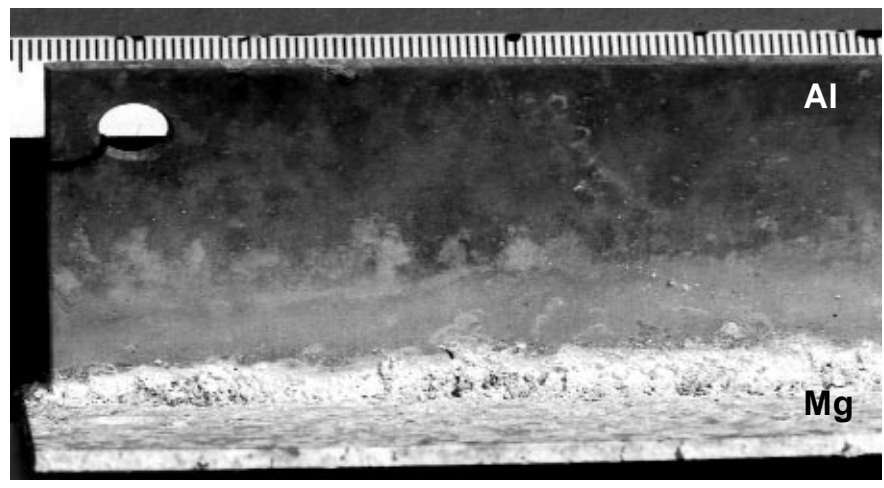

Figure 5. Uncoated hybrid sample after 30 cycles acc. to PV 1210 


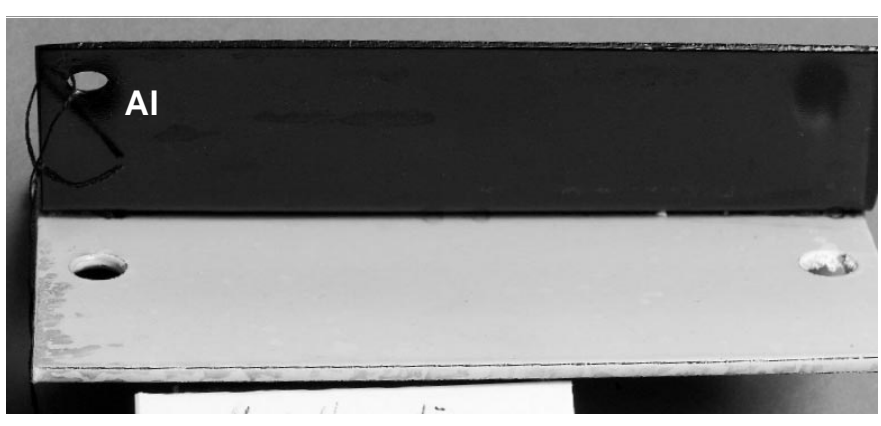

Figure 6. Hybrid sample with coating system 2 after 30 cycles acc. to PV 1210

Fig. 6 shows the typical appearance of a coated hybrid body after 30 cycles of the environmental corrosion test. No corrosion is evident in the fold zone. In this case, the isolating effect of the organic coating plays an important role. Of the 14 different coating systems, 13 are able to effectively suppress corrosion of the fold. Coating system 11 with chromated and e-coated magnesium panel is especially noteworthy. The corrosion damage tothe fold, cf. Fig. 7, is so advanced that the coating system chromation + e-coat is classified as unsuitable for magnesium body components. The paint coats applied in addition to the e-coat in car construction cannot reach the inner fold area due to the application technique. It is not possible to improve the corrosion protection of the e-coat at this point.

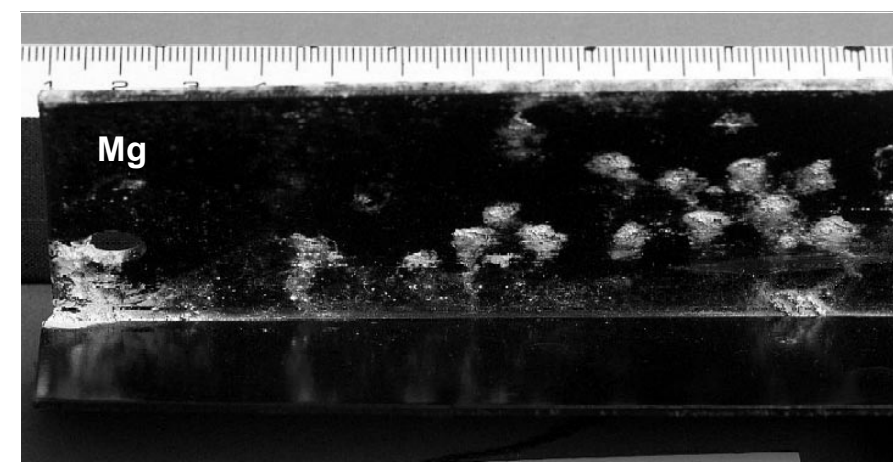

Figure 7. Hybrid sample with coating system 11 after 30 cycles acc. to PV 1210

The occurrence of corrosion on the surface of the hybrid body can be equated with the failure of the protective system. Of the total of 14 tested coating systems, only No.s 11 (e-coat) and 14 were not able to provide sufficient protection from surface corrosion. The non-organic coating system 14 consists of the anodizing layer Magoxid and is subject to heavy surface corrosion. Fig. 8 shows the hybrid body with white corrosion 'pustules', which penetrate the light gray Magoxid layer. The layer system chromation + e-coat + powder coating -preferred for protection of the hybrid construction-successfully prevents the occurrence of surface corrosion over 30 test cycles. No cases of corrosion of the e-coated aluminum panel were observed.

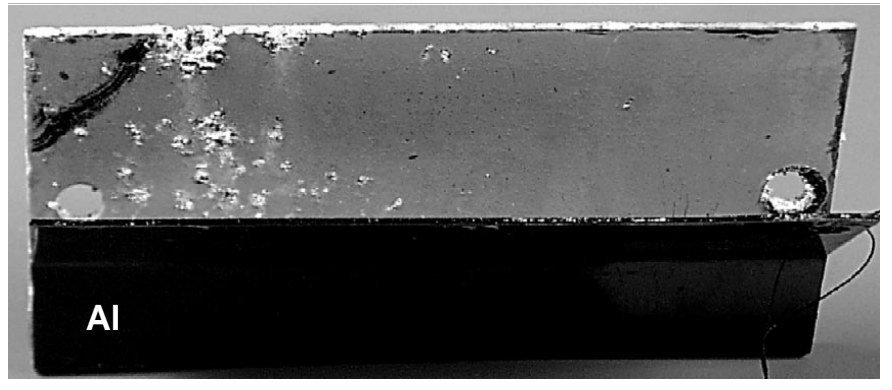

Figure 8. Hybrid sample with coating system 14 after 30 cycles acc. to PV 1210

From the perspective of corrosion prevention, components should ideally be 'edgeless'; for design and construction reasons, it is often not possible to avoid edges at component boundaries and at recesses. The wet paint system No. 7 is the most intensively affected by edge corrosion, cf. Fig. 9. The damage appears after just 5 cycles and continuously increases in its extent with time. As each of the 9 hybrid bodies with protection system 7 exhibited edge corrosion of up to $50 \%$ and this appearing quite quickly, the system was rated unsuitable. Layer system 14 showed similarly pronounced edge corrosion, cf. Fig. 8. Less striking, but still unacceptable, was the edge corrosion of layer system 11 with e-coating, cf. Fig. 7. The remaining coating systems all exhibit relatively insignificant corrosion of up to 2 percent of the edge length. The powder precipitation in the edge area is often low in the edge area due to limitations of the process. Hence the radius of curvature of the edges should be as large as possible for magnesium components foreseen for coating. If this is not possible, it is essential that the edges are sufficiently deburred. [4]

- The layer system 13 with chrome-free conversion layer provided good results in comparison with the layer systems with chromation.

- The good results for coating system 12 indicate that even without e-coat a single application of powder coat provides adequate protection from corrosion. However in practice, the application of an e-coat is a good idea. Because of the nature of the process, the paint layer accretes evenly over the whole component surface even at concealed locations.

- The double powder application of coating systems 9 and 10 leads to some improvement in the quality of finish but does not yield any improvement in corrosion performance compared with a single coat.

- It is not possible to say on the corrosion results which of the various powder coatings provides the best protection. 


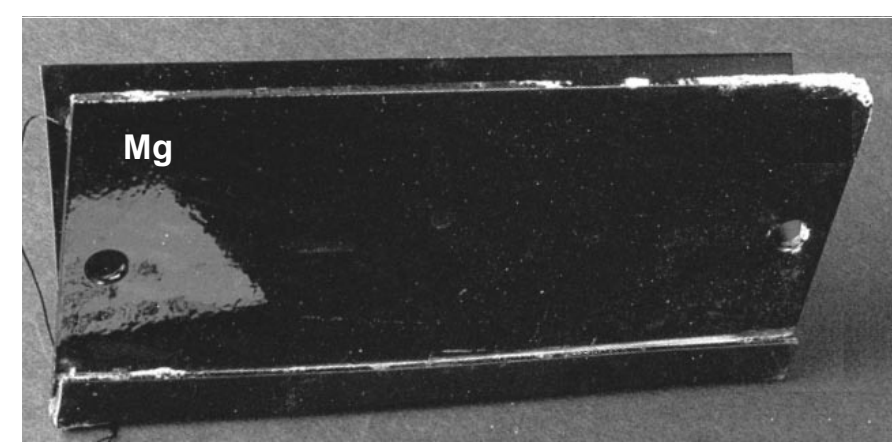

Figure 9. Hybrid sample with coating system 7 after 30 cycles acc. to PV 1210

Drill holes have been made in the magnesium sheet and the aluminum panel of the hybrid body which serve as electrical contact points during processing. Independently of which coating system is used, nearly all drill holes were affected by corrosion. It is therefore advantageous for production purposes, that the contact points are placed at non-critical locations, out of the normal field of vision.

GALVANIC SAMPLES - The results of the last section have shown how the Al-Mg hybrid structure can be effectively protected against corrosion. But what level of corrosion is to be expected when the organic coating system is damaged and the now unprotected magnesium panel in combination with an add-on component forms a single galvanic element?
For the evaluation of the test results for the contact body, the maximum propagation of the scratch in the vicinity of the contact element was determined. Fig. 10 shows the scratch propagation of the tested coating systems after 30 cycles of the environmental corrosion test. One column of the diagram represents the sum of the five individual test results for a coating system. Each of the individual results corresponds to the corrosion damage to one of the five different contact elements.

All tested organic coating systems are susceptible to contact corrosion. Fig. 11, A and B, provide typical examples of corrosion damage. The contact corrosion in the area between the scratch and the contact element in this case extends over a width between 36 and $44 \mathrm{~mm}$, in addition hole formation occurs. No contact corrosion was observed at the edges of the contact element on the support surface for the coated magnesium panel. This is the case with nearly all test bodies. If the paint coat is undamaged, no galvanic element is formed. An exception to this is formed by the magnesium panels coated in ecoat only, which are still subject to contact corrosion even when the coat is undamaged.

It does not make any difference whether the contact elements are zinc plated or zinc plated and then sealed. Although the sealed layers exhibit a rather high degree of galvanic compatibility with magnesium, [5] in this case severe corrosion damage arises. The cause is the unfavorable relationship between cathode and anode. The contact element has a large cathode surface in comparison with the scratch, resulting in a high anodic current density on the magnesium surface.

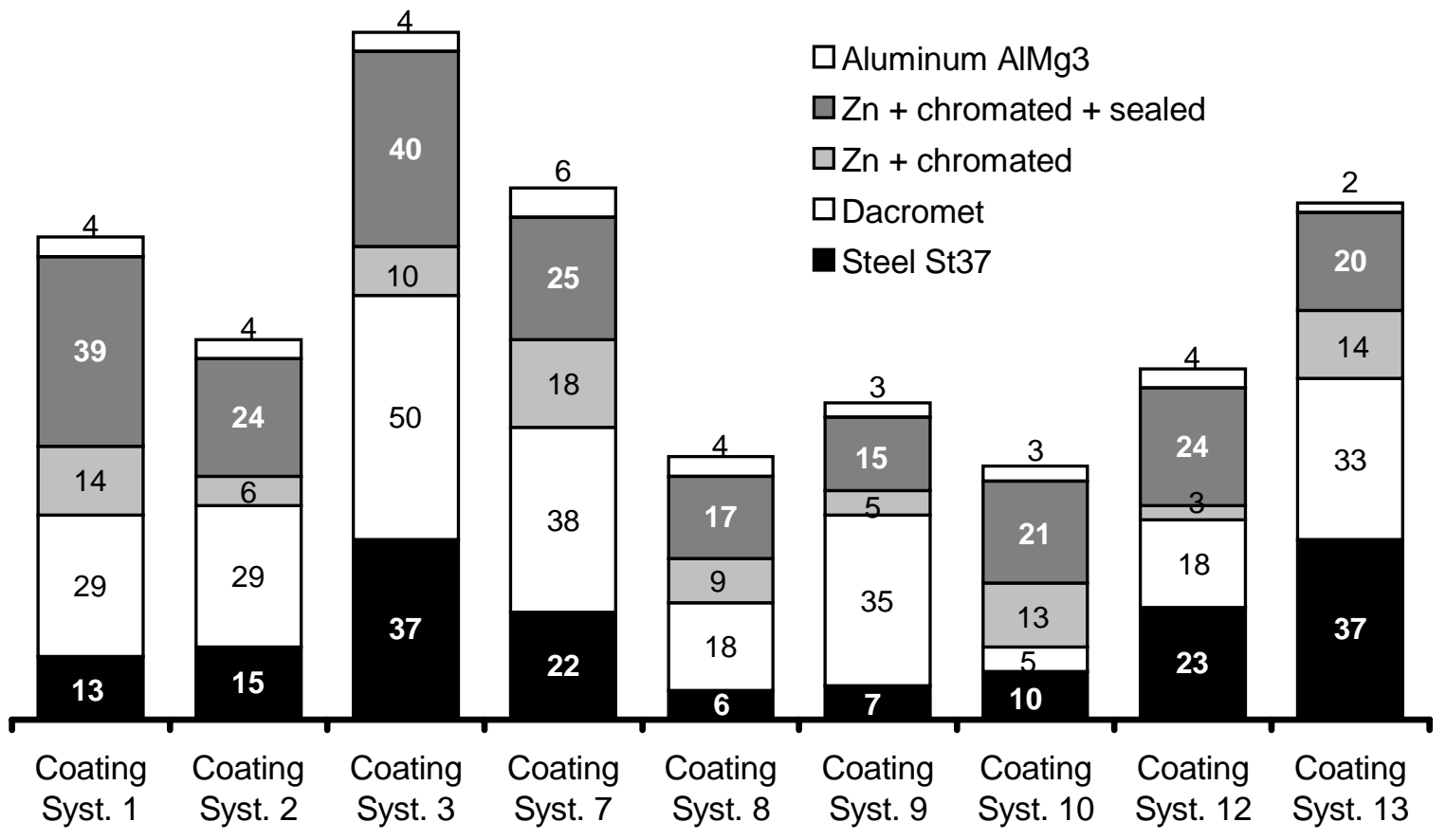

Figure 10. Scratch propagation [mm] of the galvanic samples after 30 cycles acc. to PV1210 

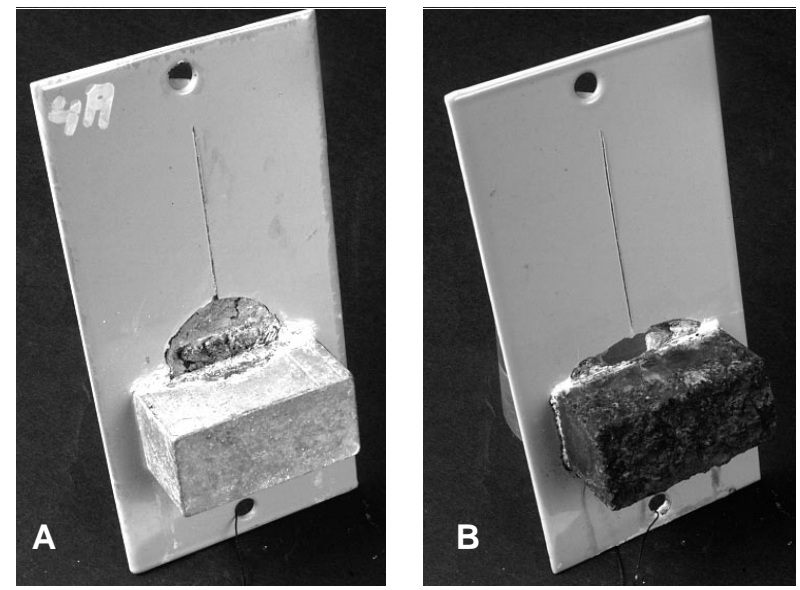

Figure 11. Galvanic samples after 30 cycles acc. to PV 1210
A) Coating system $9+$ Dacromet Contact

B) Coating system $13+$ Steel Contact

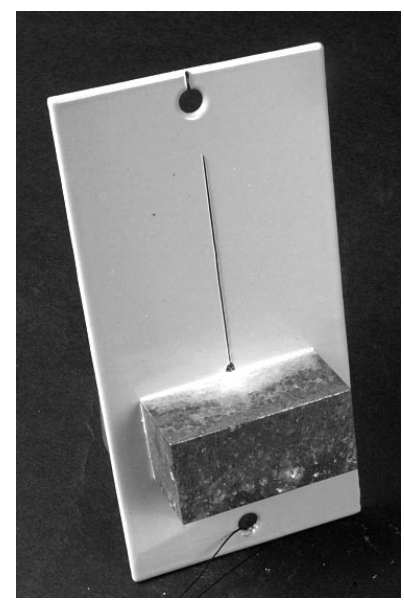

Figure 12.

Galvanic sample after 30

cycles acc. to PV 1210

Coating system $9+$

Aluminum Contact

The galvanic characteristics of aluminum contact elements are far superior. These yield a limited scratch propagation of 2 to $6 \mathrm{~mm}$, cf. Fig. 10 and perforation of the magnesium panel does not occur. Fig. 12 provides a clear example of aluminum's excellent galvanic compatibility. It is important that only slightly alloyed aluminum materials with as little copper content as possible are selected for the connecting elements. If this is not possible, it is essential that any damage to the coating of the magnesium component is avoided.

The galvanic effect of the contact element does not reach the top end of the scratch. It is possible to make statements on the general corrosion characteristics in this area. Widening of the scratch was not established with any of the tested coating systems. This indicates that the paint bonds well to the magnesium surface and can be traced back to the effect of pickling and the conversion layer.

\section{CONCLUSION}

The test results presented here have made a decisive contribution to the development of the production and coating processes for the Mg-Al hybrid hatchback of the 3 -liter car. The process steps for the internal components made from magnesium are similar to those of the coating process for the test bodies. The methods described here show how magnesium as a material for a body component, can be effectively protected against corrosion. How a corrosion protection system can be systematically developed by means of test bodies is also outlined. The preferred coating system consists of an e-coat $(20 \mu \mathrm{m})$ with an additional powder coating layer $(>80 \mu \mathrm{m})$. If the paint coat is damaged, severe contact corrosion may be expected in the vicinity of the fixings. The fixings should therefore be made of aluminum.

\section{ACKNOWLEDGEMENTS}

We would like to express our appreciation for the excellent work contributed by the research students Dirk Rüter and Marco Haesche during the tests. Special thanks also go to Wolf-Dieter Mahn and Udo Donndorf from the Benseler Group for their advice and for coating the magnesium panels.

\section{REFERENCES}

1. Hawke, D. and Gaw, K., "Effects of Chemical Surface Treatments on the Performance of an Automotive Paint System on Die Cast Magnesium", SAE Technical Paper, 920074, Detroit, 1992

2. Murray, R.W. and Hillis, J.E., "Powder Coatings on High Purity Die Casting Magnesium For Appearance and Protection", 16th International Die Casting Congress and Exposition, Detroit, 30 Sept. - 3 Oct, 1991, Publ: North American Die Casting Association, Illinois, 1991

3. Avedesian, M.M. and Baker, H. "Magnesium and Magnesium Alloys" ASM Specialty Handbook, ASM International, USA, 1999

4. Schreckenberger, H. and Laudien, G.,"Processing and corrosion control of a magnesium body structure element" Proceedings of the Euromat 99, München, Volume 1, Publ: Wiley-VCH, Weinheim (Germany), 2000

5. Haferkamp, H., Niemeyer, M., Phan-tan Tai, Kaese, V., Schreckenberger, H., Laudien, G., Koeppen, H.-J. and Lehmhus, D., "Oberflächenschutzsysteme für die Verschraubung von Magnesiumbauteilen", 6. Magnesiumguss Abnehmerseminar u. Automotive Seminar, Aalen (Germany), 30 Sept. - 1 Oct, 1998, Publ: IMA, ISBN 3-932291-16-6, 1998

\section{CONTACT}

Do not hesitate to send the authors an e-mail.

Harald.Schreckenberger@volkswagen.de

Matthias.Papke@volkswagen.de

Stephan.Eisenberg@volkswagen.de 
APPENDIX

Table A/1. Process materials

\begin{tabular}{l|l|l}
\hline \multicolumn{1}{c|}{ Process material } & \multicolumn{1}{c}{ Type } & \multicolumn{1}{c}{ Producer } \\
\hline $\begin{array}{l}\text { Powder 1: Interpon black, matt } \\
\text { Interpon 610 MN 210 G }\end{array}$ & Polyester & $\begin{array}{l}\text { Akzo Nobel Powder Coatings, } \\
\text { Bensheim, Germany }\end{array}$ \\
\hline $\begin{array}{l}\text { Powder 2: Interpon grey } \\
\text { Interpon 700 EP 000 D }\end{array}$ & Epoxy/Poyester & $\begin{array}{l}\text { Akzo Nobel Powder Coatings, } \\
\text { Bensheim, Germany }\end{array}$ \\
\hline $\begin{array}{l}\text { Powder 3: Ruhrpowder black } \\
\text { 90-84-9908-2 VEDOC High Q }\end{array}$ & Polyester & Ruhr-Powder, Arnsberg, Germany \\
\hline $\begin{array}{l}\text { Powder 4: Interpon black, rough } \\
\text { Interpon 600 JN302D }\end{array}$ & Polyester & $\begin{array}{l}\text { Akzo Nobel Powder Coatings, } \\
\text { Bensheim, Germany }\end{array}$ \\
\hline $\begin{array}{l}\text { Powder 5: Interpon black, glossy } \\
\text { Interpon 000917 }\end{array}$ & Epoxy & $\begin{array}{l}\text { Akzo Nobel Powder Coatings, } \\
\text { Bensheim, Germany }\end{array}$ \\
\hline $\begin{array}{l}\text { Powder 6: Wöralit grey } \\
\text { Wöralit W808 62942 }\end{array}$ & Epoxy/Polyester & $\begin{array}{l}\text { Karl WÖRWAG, Lack- und } \\
\text { Farbenfabrik, Stuttgart, Germany }\end{array}$ \\
\hline E-Coat (applied to Mg-Panels) & Cathodip & BASF \\
\hline Acid Pickle & Deoxydizer 395 H & Henkel \\
\hline Chromate & Alotron 5 & Henkel \\
\hline Wet paint: & & \\
Epoxy Primer \\
$\begin{array}{l}\text { PUR-AQUA-FILL } \\
\text { A.-C.Basecoat } \\
\text { 2K-HS-Clearcoat }\end{array}$ & & Kerpen, Germany \\
\hline Chrome-free pre-treatment & & AHC Oberflächentechnik, \\
\hline Magoxid & Conversion Layer & \\
\hline
\end{tabular}

